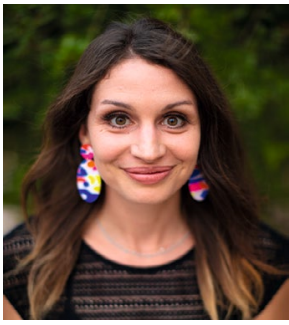

\title{
Reproductive justice must be considered in the scientific community
}

\author{
The sciences will never be a truly equitable workplace as long as patriarchy, racism and \\ oppressive social norms persist, writes Kelly Ramirez.
}

$\mathrm{n} 2016$, at the age of 31 years, I began my journey into activism. For most of my academic and career trajectories in microbial ecology, I allowed myself the privilege to remain ignorant of (or ignore) the experiences of my colleagues and peers who experienced discrimination and harassment because of their skin colour, sexual orientation, gender status, nationality and ethnicity, or disability. I could do this because I am a white, cis-hetero woman, my disability is hidden, I could afford to ignore sexual harassment aimed my way, and I was not willing to put myself or my career on the line.

The result of the 2016 US presidential election was the first time I fully acknowledged how strongly the sexism, racism, ableism, homophobia, transphobia and anti-immigration norms built into our society impact the work and success of scientists. In direct response to the election results, Dr Jane Zelikova and myself initiated 500 Women Scientists. Together with a group of friends and colleagues from diverse scientific backgrounds, we wrote an open letter that we hoped 500 women would $\operatorname{sign}^{1}$. We recognized that if we were going to tackle patriarchy and racism in our society, we needed to start in our own scientific community. Within hours, we had far exceeded our goal. Once we reached 20,000 signatures, we developed a plan to create a non-profit organization with the mission to make science more open, inclusive and accessible, by fighting racism, patriarchy and oppressive social norms. Today, we have more than 500 local chapters around the world, with more than 10,000 active participants. We launched Fellowship for the Future $^{2}$ - supporting women of colour who lead in science, technology, engineering and mathematics (STEM) - and many other projects that are recognized and used by institutions globally.

The scholarship of equity and inclusion in science shows that there are significant and recalcitrant barriers that impede women, in particular Black, Indigenous and women of colour, in science (and these barriers have only increased during the COVID-19 pandemic) ${ }^{3,4}$. These barriers can not only create a toxic environment, but may also result in the well-known leaky pipe: the gender imbalance prevalent at later career stages. Although much progress has been made to make science a more equitable environment, this is largely due to the leadership and actions of women and marginalized folx. However, institutions have slowly started to take a harder line on sexual and racial harassment and discrimination. Some programmes have been created to ease the 'motherhood penalty'; directed mentorship and scholarship programmes have been developed with Black, Indigenous and women of colour in mind; and there are now more consistent efforts being made to eliminate biases in publication, grant funding and promotion.

One barrier that remains largely ignored by institutions, policy and the media is reproductive justice. Reproductive justice "is the complete physical, mental, spiritual, political, social, and economic well-being of women and girls, based on the full achievement and protection of women's human rights", as defined by the SisterSong Women of Color Reproductive Health Collective $^{5}$. Reproductive justice means being able to choose if and how to become a parent and the freedom to raise children in safe and supportive environments. Abortion is one of the many facets of reproductive justice - around the world, the autonomy and rights of individuals with a uterus are under attack. In Texas, where I live and work, a state law named Senate Bill 8, also referred to as the 'heartbeat bill', was recently approved ${ }^{6}$. This law effectively bans all abortions after six weeks. Senate Bill 8 (which continues to be challenged in federal courts) is just one of many fights against the right to reproductive freedom and access to healthcare. As observed with past legislation ${ }^{7}$, bans and limits on abortion inevitably result in a reduction in access to other reproductive healthcare.

Any ban or restrictions on reproductive justice disproportionally impact Black,
Indigenous and other communities of colour, those in poverty and those with disabilities, preconditions or a uterus. These restrictions are oppressive and this oppression serves to control rather than protect. The toll of reduced reproductive freedoms on individuals and communities is well documented and severe ${ }^{8}$. For me, a woman with a uterus in my mid-30s that is still deciding when I will have children, this law impacts my health, my family and my career. I also consider repercussions for my students, a population entering a point in their lives where their reproductive health is a priority, who I am responsible for educating and mentoring. And for my community, with Latinx comprising $80 \%$ of the population - a population that is disproportionally impacted. Although I can afford the cost to travel to a nearby state if I ever need an abortion, many in my community do not have that luxury.

One of the most important lessons from my work with 500 Women Scientists is that if we are to truly create an equitable world, our work must centre on the most marginalized. The most marginalized population may vary by community, region and country, but the work must always return to this centre. We learned this important lesson from working and listening closely to Black, Indigenous and women of colour who are leaders in this field and who we have worked with. To focus on the most marginalized, we have built a Reproductive Justice Initiative $^{9}$, to amplify women of colour leading the fight for reproductive justice, and a Sci-Mom Journeys ${ }^{10}$ programme to advocate for mothers and others in STEM with caregiving responsibilities, and those aspiring to becoming parents. Both programmes exemplify how solutions to create inclusive and equitable science must be focused on those who are most negatively impacted. An inclusive scientific community means breaking down barriers that prevent anyone from thriving in STEM fields, and reproductive justice is a key part of this. 
What would it look like for an academic institution to implement policies or be involved in progress towards reproductive justice? Beyond providing basic education and resources, institutions should implement routine assessments that occur at hiring, as well as annually, to identify who is in most need of support and access to reproductive health measures. From there, programmes can be designed that centre on those most impacted by oppressive laws and consequently deficiency in reproductive healthcare. As individuals, this means educating ourselves, addressing our own internal biases and having conversations with friends and colleagues. As mentors and teachers, we can be prepared by knowing what resources are available to our students and pushing our administrations to broaden their diversity values. Although these oppressive laws are already in place in some areas (or threaten to be soon), we must remember to balance our sense of urgency with creating concrete long-lasting reform that supports reproductive justice in the long term.

Five years after co-founding 500 Women Scientists, I am in no way satisfied with my personal growth or impact. My path and work in social justice has not been linear and along the way I have indeed stumbled, made mistakes and even caused harm. Yet I am determined to use whatever small platform and power I have to confront the patriarchal, racist and oppressive social norms embedded within our society and I ask more in the scientific community to join me.

\section{Kelly S. Ramirez (D) 1,2凶}

${ }^{1}$ University of Texas at El Paso, El Paso, TX, USA. ${ }^{2} 500$ Women Scientists, Boulder, CO, USA.

$凶_{e-m a i l: K s r a m i r e z 4 @ u t e p . e d u}$

Published online: 4 March 2022

https://doi.org/10.1038/s41564-022-01077-0
References

1. Ramirez, K. S. An open letter from and to female scientists. Scientific American https://go.nature.com/3B51EaP (18 November 2016)

2. Fellowship for the Future (500 Women Scientists, accessed 1 February 2022); https://go.nature.com $/ 34 \mathrm{qCo} 2$ J

3. 500 Women Scientists Leadership. Silence is never neutral; neither is science. Scientific American https://go.nature.com/ 3ruCqQ2 (6 June 2020).

4. Krukowsi, A. et al. Ann. Am. Thorac. Soc. https://doi.org/10.1513/ AnnalsATS.202107-875CME (2021)

5. Reproductive Justice (Sister Song, accessed 1 February 2022); https://go.nature.com/3J9PD6J

6. Senate Bill 8 (Planned Parenthood, accessed 1 February 2022); https://go.nature.com/3B49rp9

7. Chapman, G. Who stands to lose the most under Georgia's anti-abortion bill? Atlanta https://go.nature.com/3rGcv8d (20 March 2019).

8. Rabin, R. C. Huge racial disparities found in deaths linked to pregnancy. The New York Times https://go.nature.com/3GvC27V (7 May 2019)

9. Reproductive Justice Initiative (500 Women Scientists, accessed 1 February 2022); https://go.nature.com/3J3GVqs

10. Sci-Mom Journeys (500 Women Scientists, accessed 1 February 2022); https://go.nature.com/3JczkpB

Competing interests

The author declares no competing interests. 